\title{
PENGARUH KEPUASAN KERJA TERHADAP KINERJA KARYAWAN DENGAN STRES KERJA SEBAGAI VARIABEL MEDIASI
}

\author{
Elizabeth Fauziek dan Yanuar
}

\author{
Fakultas Ekonomi dan Bisnis Universitas Tarumanagara, Jakarta \\ E-mail: elizabeth.115170215@stu.untar.ac.id
}

\begin{abstract}
This study aims to determine the effect of job satisfaction on employee performance with job stress as a mediating variable. The subjects used in this study were employees at PT. XYZ. PT. XYZ is a multinational real estate company. The number of samples taken in this study were 75 respondents. The data obtained was carried out from the results of distributing questionnaires through google form using purposive sampling technique. Processing of the collected data is carried out with the SmartPLS program. Based on the results of data analysis, it can be concluded that job satisfaction has a significant negative effect on job stress, and job stress has a significant negative effect on employee performance. Also, job satisfaction has no effect on employee performance. However, job stress can mediate the effect of job satisfaction on employee performance. This research shows that in order to improve employee performance, companies need to pay attention to employee job satisfaction in order to reduce employee work stress levels.
\end{abstract}

Keywords: Job Satisfaction, Job Stress, Employee Performance.

Abstrak: Penelitian ini bertujuan untuk mengetahui pengaruh Kepuasan Kerja terhadap Kinerja Karyawan dengan Stres Kerja sebagai variabel mediasi. Subjek yang digunakan dalam penelitian ini adalah karyawan pada PT. XYZ. PT. XYZ merupakan perusahaan di bidang real estate berskala multinasional. Jumlah sampel yang diambil dalam penelitian ini sebanyak 75 responden. Data yang diperoleh dilakukan dari hasil penyebaran kuesioner melalui google form dengan menggunakan teknik pengambilan sampel purposive sampling. Pengolahan data yang telah terkumpul dilakukan dengan program SmartPLS. Berdasarkan hasil analisis data, maka dapat disimpulkan bahwa Kepuasan Kerja berpengaruh negatif signifikan terhadap Stres Kerja, dan Stres Kerja berpengaruh negatif signifikan terhadap Kinerja Karyawan. Serta, Kepuasan Kerja tidak berpengaruh terhadap Kinerja Karyawan. Akan tetapi, Stres Kerja dapat memediasi pengaruh Kepuasan Kerja terhadap Kinerja Karyawan. Dari penelitian ini menunjukkan bahwa untuk dapat meningkatkan Kinerja Karyawan, perusahaan perlu memperhatikan Kepuasan Kerja karyawan agar dapat menurunkan tingkat Stres Kerja karyawan.

Kata kunci: Kepuasan Kerja, Stres Kerja, Kinerja Karyawan.

\section{LATAR BELAKANG}

Sumber daya manusia merupakan faktor yang paling berpengaruh dalam suatu organisasi / perusahaan. Memuaskan karyawan merupakan salah satu tantangan dalam berbisnis untuk dapat mencapai kesuksesan serta agar tetap dapat bersaing Ganesan, J., Ling, W.X., \& Mun, K.L. (2017). Dengan adanya peran sumber daya manusia dalam suatu perusahaan, maka karyawan diharapkan dapat memberikan kontribusi sehingga tujuan perusahaan akan tercapai. Oleh karena itu, pentingnya sumber daya manusia yakni kinerja 
karyawan kini perlu disadari oleh semua industri untuk dapat bersaing dan dapat mempertahankan kelangsungan hidup perusahaan. Yusuf, Muhammed, \& Kazeem (2014) menyatakan kinerja karyawan adalah kemampuan untuk mencapai tujuan yang ditetapkan dalam garis waktu dan parameter yang diperlukan. Tidak dapat dipungkiri, perlu bagi perusahaan untuk menjaga dan meningkatkan kinerja karyawannya agar menghasilkan dampak positif demi kelancaran perusahaan.

Dari banyaknya faktor yang dapat mempengaruhi kinerja karyawan, dalam penelitian Abdirahman, H. I. H. (2018) diketahui bahwa kepuasan kerja memiliki pengaruh yang signifikan terhadap kinerja karyawan, sedangkan dalam penelitian Paais, M. (2018) diketahui bahwa kepuasan kerja tidak memiliki pengaruh yang signifikan terhadap kinerja karyawan. Dengan demikian, timbul pertanyaan kritis untuk mengetahui apa yang dibutuhkan agar kepuasan kerja dapat meningkat terhadap kinerja karyawan. Maka dari itu, penelitian ini perlu menambah stres kerja sebagai variabel mediasi yang dimana sama halnya dalam penelitian Riyadi, S. (2019) bahwa kepuasan kerja akan berdampak terhadap kinerja karyawan melalui stres kerja sebagai mediasi. Dengan logika dimana kepuasan kerja yang baik akan menurunkan tingkat stres kerja dan kemudian akan meningkatkan kinerja karyawan.

PT. XYZ merupakan perusahaan real estate berskala multinasional. Adapun permasalahan yang terjadi pada perusahaan tiga tahun terakhir adalah hasil kinerja karyawan yang belum sesuai dengan harapan perusahaan, yang ditunjukkan melalui nilai Key Performance Indicator (KPI) pada tabel 1.1 berikut :

Tabel 1.1

Data KPI Karyawan PT. XYZ

\begin{tabular}{|c|c|c|c|c|}
\hline Tahun & KPI Element & $\begin{array}{c}\text { Max } \\
\text { Score }\end{array}$ & Accomplishment & Result \\
\hline \multirow{3}{*}{2018} & Disciplinary & 7 & 5 & -2 \\
\cline { 2 - 5 } & Neatness & 8 & 5 & -3 \\
\cline { 2 - 5 } & Decency & 8 & 6 & -2 \\
\cline { 2 - 5 } & Timeliness & 9 & 5 & -4 \\
\hline \multirow{4}{*}{2019} & Disciplinary & 7 & 4 & -3 \\
\cline { 2 - 5 } & Neatness & 8 & 5 & -3 \\
\cline { 2 - 5 } & Decency & 8 & 5 & -3 \\
\cline { 2 - 5 } & Timeliness & 9 & 5 & -4 \\
\hline \multirow{4}{*}{2020} & Disciplinary & 7 & 7 & -2 \\
\cline { 2 - 5 } & Neatness & 8 & 6 & -4 \\
\cline { 2 - 5 } & Decency & 8 & 6 & 0 \\
\cline { 2 - 5 } & Timeliness & 9 & 5 & -2 \\
\hline
\end{tabular}

Sumber : Data Internal Perusahaan

Dari tabel diatas, terlihat bahwa penurunan KPI menunjukkan rendahnya kinerja karyawan. Hal ini disebabkan karena masih kurangnya kepuasan kerja karyawan sehingga memicu timbulnya stres kerja yang dapat mempengaruhi kinerja karyawan PT. XYZ. 
Berdasarkan penjelasan tersebut, maka penulis tertarik untuk melakukan penelitian dengan judul "Pengaruh Kepuasan Kerja Terhadap Kinerja Karyawan Dengan Stres Kerja Sebagai Variabel Mediasi Pada PT. XYZ”.

\section{KAJIAN TEORI}

\section{Social Exchange Theory}

Dengan konsep penelitian mengenai kinerja karyawan, maka teori yang dapat mendukung penelitian ini adalah Social Exchange Theory. Teori ini dikemukakan oleh Blau (1964) yang menyatakan bahwa adanya perilaku sosial dalam interaksi dua pihak yang menerapkan analisis untuk menentukan risiko dan manfaat. Dimana karyawan yang akan melakukan pengembangan terhadap kualitas hubungan melalui dengan siapa dan bagaimana mereka berinteraksi, serta bagaimana pengalaman kerja mereka (Blau,1964).

\section{Teori Kepuasan Kerja}

Robbins dan Judge (2013) menjelaskan bahwa kepuasan kerja menggambarkan persepsi yang positif terhadap suatu pekerjaan, yang dihasilkan dari penilaian terhadap karakteristiknya. Selain itu kepuasan kerja juga merupakan respon efektifitas atau emosional terhadap berbagai aspek pekerjaan (Kreitner \& Kinicki, 2001: 271). Kepuasan kerja dapat didefinisikan sebagai akibat dari persepsi karyawan tentang seberapa baik pekerjaannya memberikan hal-hal yang dianggap penting (Luthans, 2016).

\section{Teori Stres Kerja}

Menurut Robbins (2008) stres kerja adalah suatu kondisi dinamis di mana seseorang dihadapkan pada suatu kesempatan, hambatan, atau permintaan yang berhubungan dengan apa yang sangat diinginkan dan hasilnya dianggap tidak pasti dan penting. Sedangkan menurut Newman, J. dan Beehr,T. (2000:1) juga mendefinisikan stres kerja sebagai suatu kondisi yang timbul dari interaksi antar manusia dan pekerjaan serta ditandai dengan perubahan dalam diri manusia yang memaksa mereka untuk menyimpang dari fungsi normal mereka. Stres kerja menurut Luthans (2002) juga dapat diartikan sebagai kondisi ketegangan yang mempengaruhi emosi, proses berpikir dan kondisi seorang pekerja.

\section{Teori Kinerja Karyawan}

Menurut Yanuar (2017), kinerja adalah fungsi dari kemampuan interaksi, motivasi dan kesempatan untuk tampil. Selain itu, Hameed (2011) menyatakan bahwa kinerja karyawan adalah produktivitas pegawai yang menjadi hasil pengembangan pegawai dan nantinya akan mempengaruhi efektivitas organisasi. Kinerja dalam organisasi yang menunjukkan berhasil tidaknya tujuan organisasi, dapat diukur karena keberhasilan suatu organisasi dipengaruhi oleh kinerja pegawainya (Yanuar, 2019).

Berikut model penelitian pada gambar 2.1 dibawah ini, berdasarkan uraian diatas:

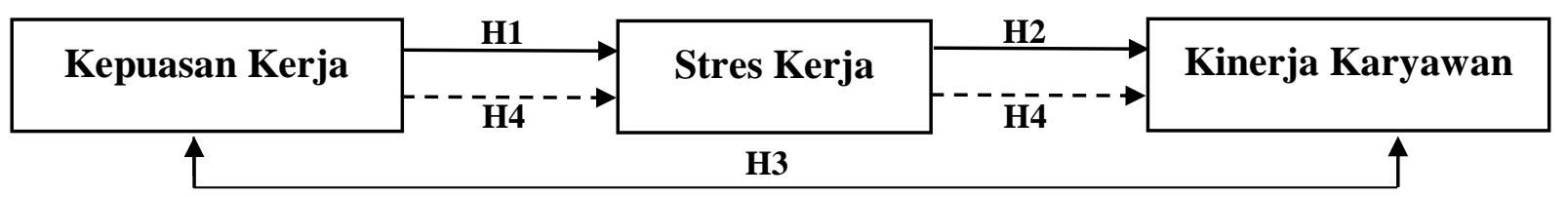

Gambar 2.1 
Model Penelitian

\section{Hipotesis}

H1 : Kepuasan kerja berpengaruh negatif signifikan terhadap stres kerja

$\mathrm{H} 2$ : Stres kerja berpengaruh negatif signifikan terhadap kinerja karyawan

H3 : Kepuasan kerja berpengaruh positif signifikan terhadap kinerja karyawan

H4 : Stres kerja memediasi pengaruh kepuasan kerja terhadap kinerja karyawan

\section{METODOLOGI}

Penelitian ini menggunakan metode deskriptif dengan menyebarkan sejumlah kuesioner secara online melalui Google Form dan dianalisis dengan pendekatan kuantitatif. Populasi dalam penelitian ini adalah karyawan PT. XYZ. Sampel yang digunakan pada penelitian ini sebanyak 75 responden. Teknik yang dipakai dalam pengambilan sampel yaitu teknik purposive sampling. Skala yang digunakan pada penelitian ini adalah skala likert, yang dimana skala ini dinyatakan dari 1 (sangat tidak setuju) sampai 5 (sangat setuju). Adapun subjek yang diteliti yaitu karyawan PT. XYZ yang diuraikan berdasarkan jenis kelamin, usia, tingkat pendidikan terakhir dan lama bekerja, serta objek penelitian ini adalah variabel-variabel yang diteliti dengan mengacu pada penelitian sebelumnya, antara lain sebagai berikut :

\begin{tabular}{|c|c|}
\hline Variabel & Indikator \\
\hline Kepuasan Kerja & 4 \\
\hline Stres Kerja & 6 \\
\hline Kinerja Karyawan & 5 \\
\hline
\end{tabular}

Sumber : Riyadi, S. (2019)

Analisis data yang akan digunakan pada penelitian ini menggunakan software Partial Least Square (PLS) dengan program SmartPLS dan metode analisis data menggunakan Structural Equation Model (SEM) yang terdiri dari 2 langkah yaitu model pengukuran (Outer Model) dan model struktural (Inner Model). Outer model terbagi menjadi dua yaitu, uji validitas dan reliabilitas. Sedangkan Inner model terbagi menjadi Koefisien Determinasi $\left(\mathrm{R}^{2}\right)$, Effect Size $\left(f^{2}\right)$, Predictive Relevance $\left(Q^{2}\right)$, Path Coefficient dan Uji Goodness of Fit (GoF).

\section{Hasil Analisis Data}

Analisis validitas pada outer model,baik convergent validity maupun discriminant validity, telah dilakukan dengan menggunakan analisis AVE (Average Variance Extracted), loading factors, dan cross loading. Hasilnya seluruh variabel dan indikator dalam penelitian ini valid untuk digunakan. Ketiga variabel tersebut juga dinyatakan reliabel, karena memiliki nilai cronbach's alpha diatas 0,6 dan nilai composite reliability diatas 0,7 (Hair et al., 2014: 102).

Berdasarkan pengujian dari inner model, hasil uji $\mathrm{R}^{2}$ menunjukkan bahwa sebesar 0,741 atau $74.1 \%$ variabel kepuasan kerja dapat dipengaruhi secara kuat oleh stres kerja. Sisanya sebesar 0.710 atau $71 \%$ pengaruh kepuasan kerja dan stres kerja kuat terhadap kinerja karyawan. Sedangkan hasil uji predictive relevance $\left(\mathrm{Q}^{2}\right)$ yang dihasilkan oleh konstruk kepuasan kerja ke stres kerja sebesar 0.474, dan kepuasan kerja serta stres kerja ke kinerja karyawan sebesar 0.469 , yang berarti hasilnya dapat memprediksi model penelitian dengan 
baik karena hasil $Q^{2}>0$ (Hair et al.,2014: 199). Hasil pengujian pada effect size $\left(f^{2}\right)$ menyatakan bahwa kepuasan kerja memiliki efek sedang terhadap kinerja karyawan, sedangkan kepuasan kerja memiliki efek besar terhadap stress kerja, dan stres kerja juga memiliki efek yang besar terhadap kinerja karyawan.

Selanjutnya pengujian terhadap nilai Goodness of Fit $(\mathrm{GoF})$ pada penelitian ini adalah sebesar 0,695. Hasil ini menunjukkan bahwa tingkat kelayakan diantara model pengukuran dan model strukural pada penelitian ini adalah besar, karena hasil $\mathrm{GoF}>0,36$. Dalam menjawab uji hipotesis, dapat dilihat dari hasil t-statistics dan $p$-values. Pada penelitian ini terlihat bahwa kepuasan kerja tidak memiliki pengaruh terhadap kinerja karyawan, sedangkan kepuasan kerja terhadap stres kerja, dan stres kerja terhadap kinerja karyawan serta kepuasan kerja ke stres kerja memiliki pengaruh terhadap kinerja karyawan.

Berikut ini adalah tabel hasil pengujian hipotesis dengan prosedur bootstrapping:

\section{Tabel 4.1}

\section{Hasil Uji Hipotesis}

\begin{tabular}{|c|c|c|c|}
\hline Variabel & Path Coefficient & t-statistics & p-values \\
\hline $\begin{array}{c}\text { Kepuasan Kerja } \rightarrow \\
\text { Stres Kerja }\end{array}$ & -0.863 & 23.548 & 0.000 \\
\hline $\begin{array}{c}\text { Stres Kerja } \rightarrow \\
\text { Kinerja Karyawan }\end{array}$ & -0.647 & 4.883 & 0.000 \\
\hline $\begin{array}{c}\text { Kepuasan kerja } \rightarrow \\
\text { Kinerja Karyawan }\end{array}$ & 0.223 & 1.635 & 0.103 \\
\hline $\begin{array}{c}\text { Kepuasan Kerja } \rightarrow \\
\text { Stres Kerja } \rightarrow\end{array}$ & 0.558 & 4.813 & 0.000 \\
\begin{tabular}{c} 
Kinerja Karyawan \\
\hline
\end{tabular}
\end{tabular}

Sumber: Hasil olah data pada Software SmartPLS 3.2.9

Berdasarkan tabel yang disajikan, H1 memiliki nilai path coefficients sebesar -0.863 , nilai $t$-statistics sebesar 23.548 atau lebih besar dari 1,96, dan nilai p-values sebesar 0.000 atau lebih kecil dari 0,05. Maka diketahui bahwa kepuasan kerja berpengaruh negatif signifikan terhadap stres kerja karyawan di PT. XYZ, sehinga H1 diterima.

Selanjutnya $\mathrm{H} 2$ memiliki nilai path coefficients sebesar -0.647 , nilai $t$-statistics sebesar 4.883 atau lebih besar dari 1,96, dan nilai p-values sebesar 0.000 atau lebih kecil dari 0,05. Maka diketahui bahwa stres kerja berpengaruh negatif signifikan terhadap kinerja karyawan di PT. XYZ, sehinga $\mathrm{H} 2$ diterima.

Kemudian H3 memiliki nilai path coefficients sebesar 0.223 , nilai $t$-statistics sebesar 1.635 atau lebih kecil dari 1,96, dan nilai p-values sebesar 0.103 atau lebih besar dari 0,05. Maka diketahui bahwa kepuasan kerja tidak berpengaruh terhadap kinerja karyawan di PT. $\mathrm{XYZ}$, sehinga $\mathrm{H} 3$ ditolak.

Berikutnya $\mathrm{H} 4$ memiliki nilai path coefficients sebesar 0.558 , nilai $t$-statistics sebesar 4.813 atau lebih besar dari 1,96, dan nilai p-values sebesar 0.000 atau lebih kecil dari 0,05. 
Maka diketahui bahwa stres kerja memediasi pengaruh kepuasan kerja terhadap kinerja karyawan di PT. XYZ, sehinga H4 diterima.

\section{DISKUSI}

Dalam hasil pengujian H1 yang menunjukkan bahwa kepuasan kerja berpengaruh negatif signifikan terhadap stres kerja karyawan pada PT. XYZ, maka hal ini sesuai dengan penelitian yang dilakukan oleh Syah et al., (2016) yang menjelaskan adanya hubungan negatif antara kepuasan kerja dan stres kerja. Karyawan yang merasa puas dalam pekerjaan mereka serta terhadap perusahaannya, cenderung memiliki keadaan mental yang lebih baik dan merasa terhindar dari stres kerja. Hal ini membuat karyawan yang memiliki kepuasan kerja tinggi cenderung memiliki tingkat stres yang rendah. Dengan demikian, peningkatan kepuasan kerja akan menyebabkan penurunan tingkat stres kerja.

Dalam hasil pengujian $\mathrm{H} 2$ yang menunjukkan bahwa stres kerja berpengaruh negatif signifikan terhadap kinerja karyawan pada PT. XYZ, maka hal ini sejalan dengan penelitian yang dilakukan oleh Alam Zeb, Gouhar Saeed and Shafiq ur Rehman (2015) yang juga menunjukkan bahwa adanya hubungan negatif yang signifikan antara stres kerja dengan kinerja karyawan. Untuk mencapai kinerja puncak, stres harus dikelola secara efektif, dengan efek negatif stres diminimalkan. Fakta bahwa mayoritas karyawan berpikir untuk meninggalkan pekerjaan mereka dan merasa bahwa perusahaan tidak mempedulikan mereka adalah cerminan dari ketidakpuasan yang sangat besar yang niscaya dapat menurunkan kinerja. Oleh karena itu kondisi kerja yang mendukung dapat menimbulkan semangat dalam diri mereka untuk dapat menjalankan tugasnya, mengurangi stres kerja dan meningkatkan kinerja karyawannya.

Dalam hasil pengujian H3 yang menunjukkan bahwa kepuasan kerja tidak berpengaruh terhadap kinerja karyawan pada PT. XYZ, maka berdasarkan persentase kuesionerpun, nilai indikator-indikator yang didapat pada variabel kepuasan kerja masih rendah. Dimana rata-rata hasil karyawan cenderung menunjukkan ketidakpuasan selama bekerja. Hal ini dapat terjadi karena karakteristik pekerjaan tidak mementingkan kepuasan melainkan lebih mengutamakan hasil kerja karyawan tersebut. Maka dapat dinyatakan bahwa kepuasan kerja dalam penelitian ini tidak dapat memprediksi kinerja karyawan. Hasil data ini membuktikan bahwa pentingnya peran variabel mediasi dalam model penelitian. Sama halnya dengan hasil penelitian yang dilakukan oleh Subakti, A.G (2013), bahwa faktor kepuasan kerja tidak memberikan pengaruh signifikan terhadap kinerja karyawan. Oleh karena itu, sebuah variabel mediasi perlu ditambahkan agar dapat memperkuat hubungan antara kepuasan kerja terhadap kinerja karyawan tersebut.

Dalam hasil pengujian H4 yang menunjukkan bahwa stres kerja memediasi pengaruh kepuasan kerja terhadap kinerja karyawan pada PT. XYZ, maka seperti yang dibahas oleh Hassan, M., Azmat, U., Sarwar, S., Adil, I. H., \& Gillani, S. H. M. (2020), kepuasan kerja dan kinerja karyawan memiliki hubungan yang sangat menarik antara satu dengan yang lain. Mendukung dalam studi penelitiannya bahwa konsep kepuasan kerja mempengaruhi kinerja seorang karyawan secara positif, pekerjaannya didasarkan pada pemikiran bahwa produk alami untuk memenuhi kebutuhan karyawan adalah kinerja mereka. Ini adalah salah satu tugas penting bagi manajer sumber daya manusia untuk memastikan kepuasan kerja karyawan. Jika karyawan di perusahaan tidak puas dengan pekerjaannya maka mereka tidak dapat melakukan pekerjaannya sesuai dengan perkiraan norma dan harapan.

Berdasarkan hasil pengujian inner model, dari tiga variabel independen yang ada dalam penelitian ini, variabel stres kerja memang menjadi variabel kunci yang dapat menurunkan 
kinerja karyawan, dimana stres kerja ini akan sangat mudah terbentuk saat karyawan mulai merasa tidak puas bekerja di perusahaan.

\section{PENUTUP}

Berdasarkan hasil penelitian dan pembahasan yang telah dilakukan dalam penelitian ini, maka dapat disimpulkan bahwa terdapat pengaruh negatif signifikan antara kepuasan kerja terhadap stres kerja, terdapat pengaruh negatif signifikan antara stres kerja terhadap kinerja karyawan, tidak terdapat pengaruh antara kepuasan kerja terhadap kinerja karyawan, dan stres kerja dapat memediasi pengaruh kepuasan kerja terhadap kinerja karyawan di PT. XYZ.

Penelitian ini memiliki beberapa keterbatasan dalam meneliti, yang dimana penelitian ini dibatasi dengan penggunaan satu variabel bebas dan satu variabel mediasi untuk menjelaskan kinerja karyawan, antara lain yaitu kepuasan kerja dengan stres kerja sebagai variabel mediasi dan kinerja karyawan. Dalam penelitian ini juga, akses terhadap responden terbatas sehingga penyebaran kuesioner dilakukan secara online.

Sedangkan saran dari hasil penelitian ini bagi perusahaan yaitu perlu untuk mengevaluasi kembali terhadap faktor yang membuat karyawan merasa tidak puas, merasa stres khususnya dengan membuat rasa nyaman terhadap karyawan selama bekerja untuk mengurangi kecemasan dan keterlambatan dalam menyelesaikan tugasnya sehingga agresifitas dalam menanggapi sesuatu yang terjadi di perusahaan pada karyawan dapat meningkat. Kemudian juga dengan memberikan kemudahan atau keringanan yang sesuai atas pemberian beban kerja atau target yang ingin dicapai, serta perlu menjaga hubungan baik antar rekan kerja di perusahaan serta memperhatikan faktor yang membuat buruk kinerja karyawan. Hal tersebut bertujuan agar dapat memperbaiki tingkat kepuasan kerja, stres kerja dan kinerja karyawan untuk menjadi lebih baik.

Kemudian, saran untuk penelitian selanjutnya diharapkan agar dapat memperluas penelitian dengan meneliti di skala industri agar populasi penelitian bertambah dan memberikan hasil yang lebih kuat. Serta diharapkan untuk dapat memperbesar jangkauan penelitian dengan menambah variabel-variabel lain untuk diteliti yang diduga dapat berpengaruh terhadap kinerja karyawan diluar dari variabel kepuasan kerja dan stres kerja, misalnya seperti lingkungan kerja, motivasi kerja dan lain sebagainya. Sehingga, hal ini berguna agar dapat menghasilkan informasi yang lebih baik dalam membuat keputusan pada kinerja karyawan.

\section{DAFTAR PUSTAKA}

Abdirahman, H. I. H. (2018). The relationship between job satisfaction, work-life balance and organizational commitment on employee performance. Journal of Business and Management, 20(5), 76-81.

Blau, P. M. (1964). Justice in social exchange. Sociological inquiry, 34(2), 193-206.

Ganesan, J., Ling, W.X., \& Mun, K.L. (2017). Determinants of Employee Job Satisfaction in the Malaysian manufacturing Sector. Research Journal of Applied Sciences, 12, 449-454.

Hair, J. F., Sarstedt, M., Hopkins, L., \& Kuppelwieser, V. G. (2014). Partial least squares structural equation modeling (PLS-SEM): An emerging tool in business research. In European Business Review (Vol. 26, Issue 2, pp. 106- 121). Emerald Group Publishing Ltd. https://doi.org/10.1108/EBR-10-2013-0128 
Hameed, A., \& Waheed, A. (2011). Employee development and its affect on employee performance a conceptual framework. International journal of business and social science, 2(13).

Hassan, M., Azmat, U., Sarwar, S., Adil, I. H., \& Gillani, S. H. M. (2020). Impact of Job Satisfaction, Job Stress and Motivation on Job Performance: A Case from Private Universities of Karachi. Kuwait Chapter of the Arabian Journal of Business and Management Review, 9(2), 31-41.

Kreitner, R., \& Angelo K. (2001). Organizational behavior, (5th ed.). Irwin McGraw-Hill.

Luthans, F. (2002). The need for and meaning of positive organizational behavior. Journal of Organizational Behavior: The International Journal of Industrial, Occupational and Organizational Psychology and Behavior, 23(6), 695-706.

Luthans, F. (2016). Perilaku Organisasi. Dalam D. J. Priansa, Perencanaan dan Pengembangan SDM. Bandung: Alfabeta.

Newman, J. and Beehr, T. "Personal and Organizational Strategies for Handling Job Stress: A Review of Research and Opinion", Personnel Psychology 1979; Spring: 1-44.

Paais, M. (2018). Effect of work stress, organization culture and job satisfaction toward employee performance in Bank Maluku. Academy of Strategic Management Journal, $17(5), 1-12$.

Riyadi, S. (2019). The Influence of job satisfaction, work environment, individual characteristics and compensation toward job stress and employee performance. International Review of Management and Marketing, 9(3), 93-99.

Robbins, P.S. (2008), Perilaku Organisasi Jilid 1. Jakarta: PT. Indeks Kelompok Gramedia.

Robbins, S. P. \& Judge, T. A., (2013). Organizational Behavior. 15 ed. New Jersey: Pearson Education.Rousseau, D. M. (1989). Psychological and implied contracts in organizations. Employee responsibilities and rights journal, 2(2), 121-139.

Subakti, A. G. (2013). Pengaruh motivasi, kepuasan, dan sikap kerja terhadap kinerja karyawan di Café X Bogor. Binus Business Review, 4(2), 596-606.

Syah, R. N., \& Indrawati, E. S. (2017). Hubungan antara kepuasan kerja dengan stres kerja pada sopir bus PO Agra Mas (Divisi AKAP) jurusan Wonogiri-Jakarta. Jurnal Empati, 5(3), 543-548.

Yanuar, Y. Job Performance and Government Banks: Evidence from Indonesia. Job Performance and Government Banks: Evidence from Indonesia.

Yanuar, Y. (2017). Compensation, motivation and performance of employees: Evidence from Indonesia. Journal of Economic \& Management Perspectives, 11(4), 486-492.

Yusuf, M. O., Muhammed, U. D., \& Kazeem, A. O. (2014). Management of leadership style: An approach to organizational performance and effectiveness in Nigeria. International Journal of Humanities Social Sciences and Education, 1(2), 17-29.

Zeb, A., Saeed, G., \& ur Rehman, S. (2015). The Impact of job stress on employee's performance: Investigating the moderating effect of employees motivation. City University Research Journal, 5(1), 120-129. 